\title{
Assessment of the Suitability of Reconfigurable Design Through Simulation and Decision Trees
}

\author{
Ricardo I. Ramírez Guzmán, Mario L. Chew Hernández, Mtro. L. Viveros Rosas, Ricardo R. Figueroa
}

\begin{abstract}
Positioning of the equipment of a manufacturing company is done foreseeing that it will remain fixed for a long time. This is because changes in the plant layout are thought to be costly, as they involve redesigning equipment support services, developing new foundations, using heavy machinery to move equipment, and causing non-productive time at the plant. However, the increased competition due to globalization, lead us to consider the alternative of making modifications to the layout more frequently to improve productivity. Changing the position of the equipment can be facilitated by specifying smaller mobile process equipment or by anticipating the availability of services at different points in the workshop and the existence of cranes or other means of transportation [2]. These forecasts, result in a greater investment in elements that, at least initially, do not generate any profit.

This work shows the evaluation of the feasibility of modifying the positions of the equipment when there are variations in the probability distribution in production speeds. This evaluation is carried out using decision trees and process simulation. The case study addressed consists of a generic production line with serial workstations. Jobs arrive at the first computer and join their product on hold if space is available, otherwise the job is lost. In the same way, the product on hold of the other teams are limited in size, and when a product on hold is full, the team behind stops until there is space available. Due to the use, the speeds of the equipment are changing with respect to the ones they had when new: the process times are increasing and / or becoming more variable. To improve productivity under the new process speeds, the space between the equipment can be modified, however, during this change, production must be suspended.

This work shows how, by simulating processes and decision trees, it is possible to determine the ranges of values of the suspension time and the cost of transport for which it is convenient to make changes in the spacing of the equipment.
\end{abstract}

Index Terms-Layout, Manufactures, Design, Efficiency, Equipment, Reconfigurable.

\section{INTRODUCTION}

The design of the layout of a manufacturing company is carried out with the intention that it be maintained for a minimum of three years of operation since the changes in the plant are costly, as they may involve the redesign of the support services for the equipment, elaboration of new foundations, use of heavy machinery for the movement of equipment and non-productive time in the plant [1].

However, plant layout can be designed with it in mind to some degree easy to modify (reconfigurable): Smaller, more mobile process equipment, redundant production lines can be defined.

The increasing uncertainty about the production mixes (quantity and type of processed products) brought about by globalization and the increase in competition, force us to consider the option of making modifications to the layout more frequently. Furthermore, possible technological improvements and process innovations can be better exploited if the layout is changed to adapt to them, instead of staying the same.

Initially, the plant layout can be designed with some degree of ease of modification (reconfigurable): Smaller, more mobile process equipment, redundant production lines, availability of services at different points in the shop, and / or existence of cranes or other means of moving equipment. These forecasts lead to a more expensive and less efficient plant distribution.

\section{LAYOUT}

Design is a very important topic when talking about a company, you will find the disposition or the consistent design in the location of the different sectors or departments in a factory or service facilities, as well as the equipment within them [3].

The purpose pursued with the design analysis is an optimal allocation of the plant space based on the resources used. The location of resources and their interaction is a decision of vital importance for the success of the Production System.

The space becomes an important analysis of the production processes. The before mention covers every part of the production process, from the moment the raw materials are received, to the shipment of the finished product. This process must be efficient and economical.

The benefits when is flexible design is that it can be efficiently practical, optimizing space improves station flow and increases productivity.

\section{FRAMEWORK}

A company that manufactures Product 1 (P1), with a production sequence (S1) of M1 |M2 |M3 is considered.

The design demand of the machines is QD units per unit of time. Efficiency (in \%) depends on its operating point (q), expressed as \% of design capacity. This efficiency can refer to the cost or time required to process each part. (fig.1)

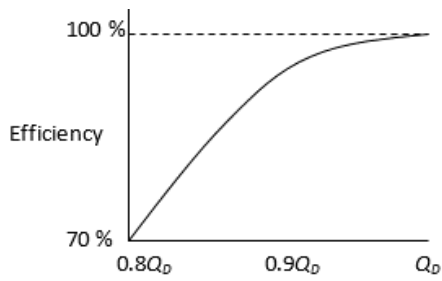

Fig. 1. Layout 1 and 2 plant distributions are designed for a $Q$ flow of product $\mathrm{P} 1$ 


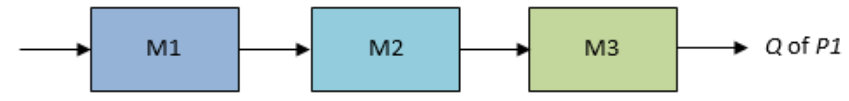

Fig. 2. Layout 1

The purchase of smaller equipment is shown in Layout 2, of equipment with half the capacity of $\mathrm{Q}$.

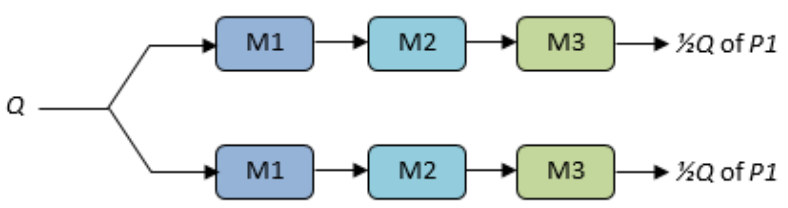

Fig. 3. Layout 2

Given the economies of scale, the cost of purchase and installation (CC\&I), labor (CMO) and material handling (CMM) of Layout 2 is greater than that of Layout 1. By means of simulation, the advantages of Layout will be evaluated 2 with respect to Layout 1, regarding the following dimensions.

\section{A. Robustness with regard to breakdowns and departure} from the point of operation of the design capacity

Design 2 is more robust compared to machine breakdowns. The convenience of maintaining Layout 2 instead of 1 due to this quality depends on the probability distributions of the time between decompositions $\left(\Delta \mathrm{t}_{D}\right)$ and the repair time $\left(\Delta \mathrm{t}_{R}\right)$, as well as the consequence of not having production or seeing it diminished (which can be the loss of customers for not having enough inventory).

Likewise, if the operating point falls below the design point, the efficiency loss of Layout 2 is less than that of Layout 1 , since in the former, at least one machine set can be maintained at its capacity of design.

\section{B. Robustness with respect to changes in the composition} of the production mix.

Consider that the design is for P1, but it may be that, due to changes in customer demand or tastes, in the near future a second product P2, with operation sequence M1 | M3 | M2, must be manufactured in the same plant. Of the total demand $\mathrm{Q}$, the quantity $(\alpha \mathrm{Q})$ corresponds to $\mathrm{P} 1$ and the quantity (1$\alpha)$ Q corresponds to P2. Under this scenario, the operation of the Layouts is illustrated below.

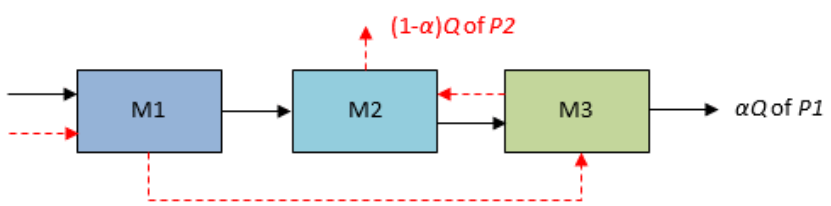

Fig. 4. Design Layout 1 and two products, $\mathrm{P} 1$ and $\mathrm{P} 2$

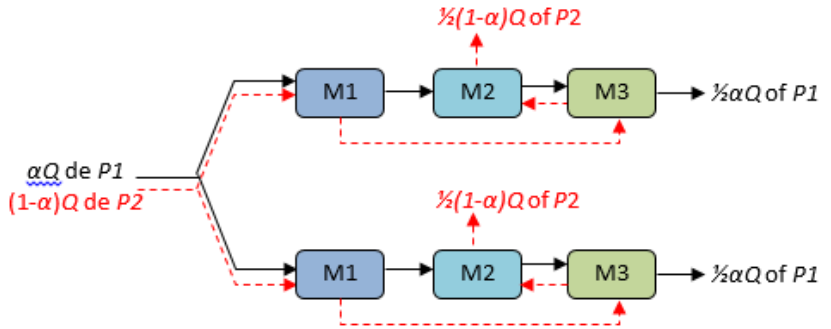

Fig. 5. Design Layout 2 and two products, P1 and P2

If the value of $\alpha$ is close to 0.5 , Design 2 can dedicate a production train to each of the parts. This can be an important advantage if there is a necessary tooling change between products $\mathrm{P} 1$ and $\mathrm{P} 2$.

If the $\alpha \approx 0.5$ condition is maintained for a long time, design 2 can be reconfigured as.

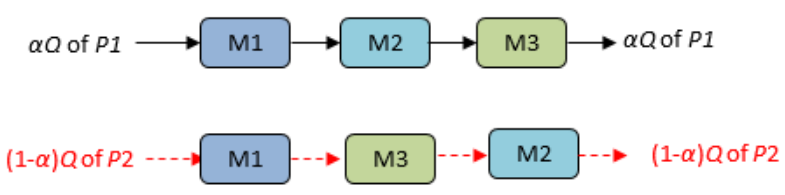

Fig. 6. Design Layout 2 and two products, P1 and P2

\section{Adjustments in plant space for local work-in-process warehouses.}

We now consider the physical space of the workshop. Each machine is assigned a space for its "work in progress", that is, the jobs that product on hold to enter that machine. The space for work in progress (WIP, or "Work in Progress") is shown in the figure below ( fig.7).

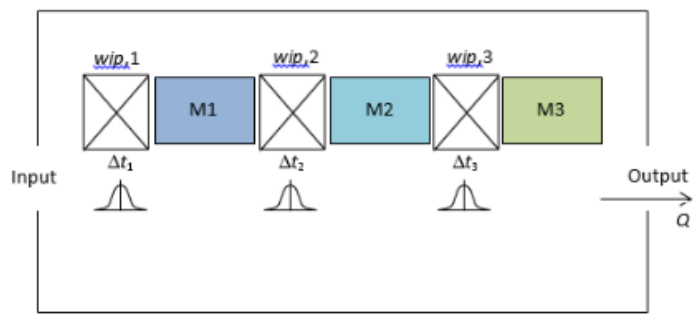

Fig. 7. Space between machines on Work in Process (WIP)

When a work-in-progress area of a machine fills up, the operation of the back machine stops. When designing the design, this is done based on the probability distribution of the speed $\left(\Delta \mathrm{t}_{i}\right)$ of new machines. Productivity under this scheme is $\mathrm{Q}$ pieces per day.

Machine time may be more variable than expected due to factors ranging from aging of the machine to the skill of the operators. Assuming machine 2 ages faster than machine 1 or 3 , the working space in this machine's process will be completely full and machine 1 should be subject to multiple stop / start operations. Productivity, with this probability distribution at the speed of machine 2, is Q '.

One way to increase productivity is to use area " $\mathrm{A}$ " as a temporary warehouse for the pieces that do not fit in the WIP, 2 , however, it will be necessary to consider the transit times from this area to the tail of machine 2 . When both "A" and $W I P, 2$ are full, machine 1 stops. The productivity observed with this configuration is Q ". (fig.8)

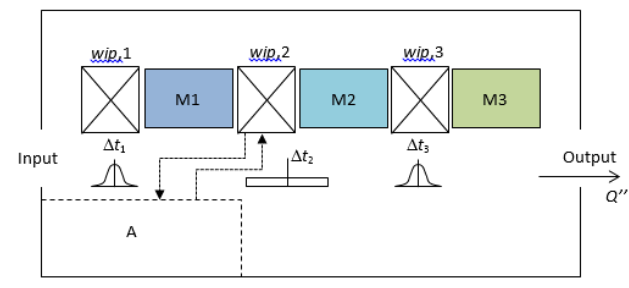

Fig. 8. Area "A" as temporary warehouse

Different values of area A would provide different productivity. Finally, by moving the equipment you can adjust the work area in the process of machine 2, as shown in the figure below (fig.9). Under this scheme, productivity is Q ,', The increase in productivity due to the adjustment must be balanced with the cost implied by the interruption of 
production to carry out the movements.

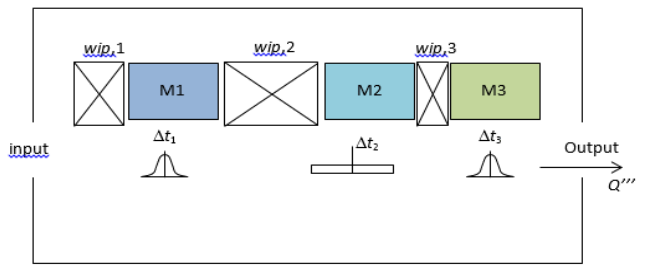

Fig. 9. Adjusted working area in machine process 2

\section{CASE Study}

A plant with three machines / processes (M1, M2, M3) is considered, the maximum sizes of the tails of these processes are denoted as NMAX, $\mathrm{i}(\mathrm{i}=1-3)$. The company can receive two types of jobs (Piece), called piece type 1 and type 2 . The processing sequence for type 1 parts is $\mathrm{M} 1 \rightarrow \mathrm{M} 2 \rightarrow \mathrm{M} 3$ and for type $2 \mathrm{M} 2 \rightarrow \mathrm{M} 3 \rightarrow \mathrm{M} 1$.

Upon arrival, Type 1 parts will try to join the tail of the M1 machine, and Type 2 parts to that of the M2 machine. If, on arrival, a part finds the tail of the machine to which it must be incorporated is full, the job (the part) is lost. In addition, a machine "locks up" if the product on hold to receive the part it has just processed does not have space to receive it.

Initially, machines can order following the order of the product process 1 . We call this arrangement configuration 1 (C1), the route that the pieces of each type must follow under that configuration is shown (figure 10).

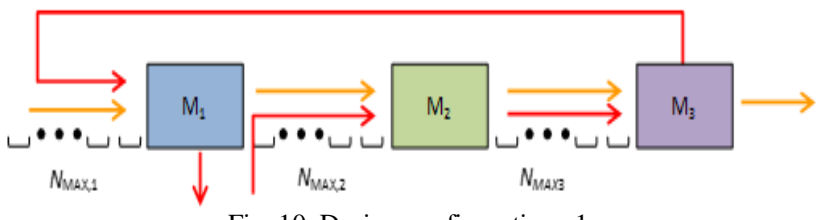

Fig. 10. Design configuration c1

In Configuration 2 (C2), the machines are arranged by following the Part 2 process path, as shown below. (fig.11).

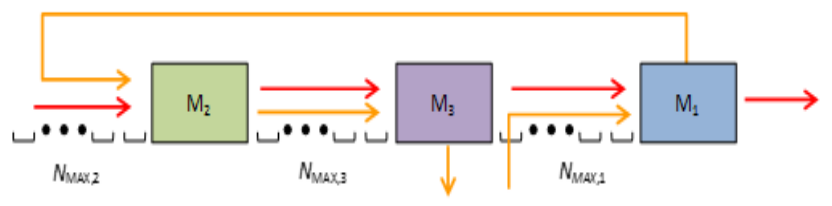

Fig. 11. Design configuration c2

If in a run the number of pieces 1 and 2 produced is $\mathrm{N}_{P, 1}$ and $\mathrm{N}_{P, 2}$, the gain of operation $\mathrm{G}$, depends on the configuration used. Given configuration $\mathrm{C} 1$, we have.

$G(C 1)=g_{P, 1} \times N_{P, 1}+g_{P, 2} \times N_{P, 2}-c_{T} \times k \times\left\{\left(N_{M A X, 1}+\right.\right.$ $\left.\left.N_{M A X, 2}+N_{M A X, 3}\right) \times N_{P, 1}+\left(N_{M A X, 1}+2 N_{M A X, 2}+2 N_{M A X, 3}\right) \times N_{P, 2}\right\}$

And for the $\mathrm{C} 2$ configuration, the gain is.

$G(C 2)=g_{P, 1} \times N_{P, 1}+g_{P, 2} \times N_{P, 2}-c_{T} \times k \times\left\{\left(2 N_{M A X, 1}+2 N_{M A X, 3}+N_{M A X, 2}\right)\right.$ $\left.\times N_{P, 1}+\left(N_{M A X, 2}+N_{M A X, 3}+N_{M A X, 1}\right) \times N_{P, 2}\right\}$

Where $\mathrm{gP}, 1$ and $\mathrm{gP}, 2$ are the unit net gains for pieces 1 and 2, respectively. Transport costs are given by the maximum lengths of the product on hold $\mathrm{s}$, where cT is the cost of moving a piece per unit length $(\$ / \mathrm{m})$ and $\mathrm{k}$ is the length of a piece in the product on hold ( $\mathrm{m} /$ piece).

The layout design consists of two stages (decisions) D1 and
D2, which are addressed sequentially

\section{D1. Select the general configuration of the plant: $\mathrm{Cl}$ or $C 2$}

D2. Decide the maximum sizes of the product on hold $s: N$ $M A X, 1, \quad N_{M A X, 2}$ and $N_{M A X, 3}$

In this investigation, we seek to explore the benefit of modifying initial decisions in view of the fact that the production mix (ratio of jobs 1 and 2) deviates from its original specification. For this, we use a simulation model of the system.

\section{Optimizing the Size of Production ON Hold}

Based on the simulation model, the decision of the plant configuration and the size of the tails can be represented by the following influence diagram. In these diagrams, the decisions are represented as squares and the uncertain events as ovals. (fig.12).

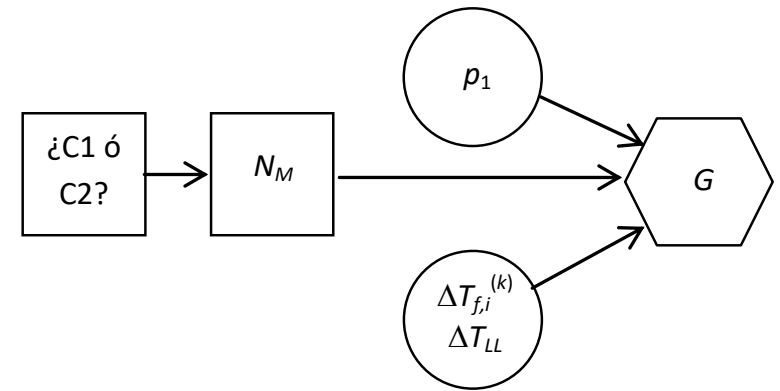

Fig. 12. Configuration and production size can be represented by influence diagram.

Given a configuration, the optimization of the number of product on hold s comes from an initial value of $N_{M A X, 1}{ }^{0}$, $N_{M A X, 2^{0}}$ and $N_{M A X, 3^{0}}$ and using simulation to carry out each evaluation. Initially, $N_{M A X, 1}{ }^{0}+1$ and $N_{M A X, 1}{ }^{0}-1$ are tested to find the direction that $\mathrm{G}$ increases with $N_{M A X, 1}$. Once this address is found, continue increasing $N_{M A X, 1}$ until finding the value that provides a maximum, say $N_{M A X, 1}{ }^{*}$. We then proceed with $N_{M A X, 2}$ y $N_{M A X, 3}$, as shown in the following figure, where it is assumed that the improvement direction of G for $N_{M A X, 1}$ y $N_{M A X, 3}$ is increasing it with respect to, respectively, $N_{M A X, 1}{ }^{0}$ y $N_{M A X, 1}{ }^{0}$, while that of $N_{M A X, 2}$ is decreasing it with respect to $N_{M A X, 2^{0}}$.

\section{RECONFIGURABLE LAYOUT}

The operation of the Reconfigurable Layout, more precisely, is as follows. Let $\mathrm{T}$ be the planning horizon. At the time of opening, the plant operates under a $\mathbf{C}_{0}$ configuration and a spacing between $\mathbf{N}_{\mathbf{0}}$ machines. After the time $\mathrm{t} 1$ has passed, the company has already identified the value of $\mathrm{p} 1$ and can change to the $\mathbf{C}_{\mathbf{N}}$ configuration and $\mathbf{N}_{\mathbf{N}}$ machine spacing with which it will operate the rest of the planning horizon. If you decide to make any changes, you will incur the lost time $\Delta \mathrm{t}_{\mathrm{p}}$. (fig.13).

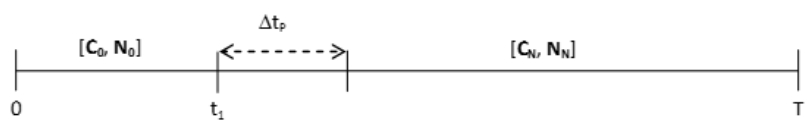

Fig. 13. Time of process 
If the profit per unit of time given the configuration $\mathbf{C}$, the spacing $\mathbf{N}$ and the proportion of product type $1 p_{1}$ as $\mathrm{g}\left(p_{1},[\mathbf{C}, \mathbf{N}]\right)$ the total profit of the operation under the reconfigurable layout $G_{L R}$ is calculated as.

$$
\mathrm{G}_{\mathrm{LR}}=\mathrm{t}_{1} \times \mathrm{g}\left(\mathrm{p}_{1},\left[\mathbf{C}_{\mathbf{0}}, \mathbf{N}_{\mathbf{0}}\right]\right)+\left(\mathrm{T}-\mathrm{t}_{1}-\Delta \mathrm{t}_{\mathrm{P}}\right) \times \mathrm{g}\left(\mathrm{p}_{1},\left[\mathbf{C}_{\mathbf{N}}, \mathbf{N}_{\mathrm{N}}\right]\right)
$$

If the time lost by changing the spacing between machines without changing the configuration is called $\Delta \mathrm{t}_{\mathrm{N}}$ and the time lost by changing the configuration $\Delta \mathrm{t}_{\mathrm{C}}$, then.

\section{$\Delta t_{\mathrm{P}}=0$ si $\mathbf{C}_{\mathbf{0}}=\mathbf{C}_{\mathbf{N}}$ y $\mathbf{N}_{\mathbf{0}}=\mathbf{N}_{\mathbf{N}}$ \\ $\Delta \mathrm{t}_{\mathrm{P}}=\Delta \mathrm{t}_{\mathrm{N}}$ si $\mathbf{C}_{\mathbf{0}}=\mathbf{C}_{\mathbf{N}}$ y $\mathbf{N}_{\mathbf{0}} \neq \mathbf{N}_{\mathbf{N}}$ \\ $\Delta \mathrm{t}_{\mathrm{P}}=\Delta \mathrm{t}_{\mathrm{C}}$ si $\mathbf{C}_{\mathbf{0}} \neq \mathbf{C}_{\mathrm{N}}$}

A change in configuration takes longer than a change in machine spacing, so $\Delta t_{C}>\Delta t_{N}$

In the case of Fixed Layout, the configuration and spacing remain constant throughout the planning horizon, calling these as $\mathbf{C}_{\mathbf{F}}$ and $\mathbf{N}_{\mathbf{F}}$, the gain of the Fixed Layout $\mathrm{G}_{\mathrm{LF}}$ is.

$$
\mathrm{G}_{\mathrm{LF}}=\mathrm{T} \times g\left(p_{1},\left[\mathbf{C}_{\mathbf{F}}, \mathbf{N}_{\mathbf{F}}\right]\right)
$$

If the variable $\mathrm{p} 1$ can take the $p_{1}{ }^{i}$ with the probability $P\left(p_{1}{ }^{i}\right)$, the expected value of the gain of the reconfigurable layout will require evaluating the following decision tree. (fig.14)

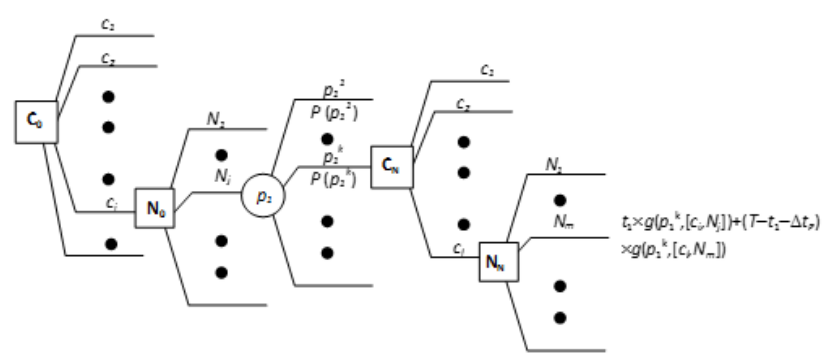

Fig. 14. Decision tree

Where $c_{i}$ is the alternative $i$ of configuration and $N_{j}$ the alternative $j$ of spacing between machines. The evaluation of this tree provides the expected value of the gain obtained when using a reconfigurable layout $\mathrm{E}\left[G_{L R}\right]$. On the other hand, the expected value of profit when having a fixed layout $\mathrm{E}\left[G_{L F}\right]$.

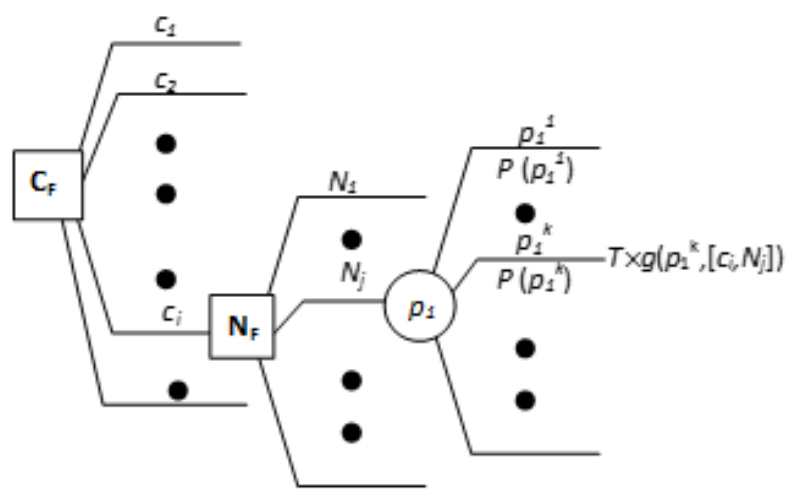

Fig. 15. Solving decision tree
The value of the reconfigurable layout can be calculated as the difference between the expected value of the first decision tree minus the expected value of the second, in other words.

$\Delta G_{L R}=\mathrm{E}\left[G_{L R}\right]-\mathrm{E}\left[G_{L F}\right]$

\section{CONCLUSION}

Among the benefits of having a flexible design is that it can be efficiently practical, with high applicability in different production requirements.

The liberation or optimization of the space necessary for the improvement of the flow of the stations and the personnel, therefore, this will resume in the increase of the productivity.

Simpler production process to follow and control. Reduction or extraction of distances and times dedicated to transport and storage, therefore, reduction or elimination of tasks that are not in accordance with the value and unnecessary costs.

With the reconfigurable design and leaner machinery, we can make operations more flexible, adjusting better to fluctuations in demand.

\section{REFERENCES}

[1] National Research Council, Visionary Manufacturing Challenges for 2020, 1998, National Academy Press, Washing, D.C. Copyright C 2017 National Academy of Sciences.

[2] Design and Analysis of Reconfigurable Layout Systems Sundersh Heragu, Gang Meng and Henk Zijm, Jan Kees Van Ommeren., 2001.

[3] Selection of layout Configuration for Reconfigurable Manufacturing Systems using the ahp, M. Reza Abdi,

[4] Dirección y Administración de las operaciones: Chase/Aquilano. Editorial Addison-Wesley Iberoamericana, 1994 Pág. 454 - 478.

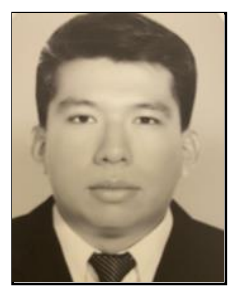

Ricardo I. Ramírez Guzmán born in the State of Mexico, Mexico, on September 1, 1999. Graduated from the Mecatrónica Engineering bachelor degree, at Universidad del Valle de México, in Mexico City, Mexico in 2014, He is currently studying the Master of Science in Industrial Engineering at Tecnológico de Estudios Superiores de Coacalco, Mexico.

He worked at Cuprum de México S.A. de C.V., Tlalnepantla de Baz, México, as Maintenance Supervisor of the foundry and vertical painting . 2013-2014., At Ashcroft de México S.A. de C.V., Naucalpan, México, As production / maintenance manager, 2014-2016. , Instituto Mexicano del Seguro Social, Mexico, As chief of conservation of medical area, 2016-2018. , Saehaesung Alabama Inc, Georgia Alabama. United States, Assembly Line Maintenance Supervisor. 2018-2019. , Universidad del Valle de México, Coacalco, México, Master of the course in Mechatronic Engineering, 2019-Present.

PhD.Chew, Doctor of Philosophy, University of Nottingham, England. Full-time Professor / Researcher Tecnológico de Estudios Superiores de Coacalco, Master in quality, science and technology, Universidad de Tlaxcala, Mexico. Full-time Professor / Researcher at Tecnológico de Estudios Superiores de Coacalco. 